\title{
Notching up neural stem cell homogeneity in homeostasis and disease
}

\author{
Claudio Giachino and Verdon Taylor* \\ Department of Biomedicine, University of Basel, Basel, Switzerland
}

\section{Edited by:}

Paolo Peretto, Università Degli Studi

di Torino, Italy

\section{Reviewed by:}

Armen Saghatelyan, Université Laval, Canada

Harold Cremer, Centre National de la Recherche Scientifique, France

\section{*Correspondence:}

Verdon Taylor, Department of Biomedicine, University of Basel, Mattenstrasse 28, 4058 Basel, Switzerland

e-mail:verdon.taylor@unibas.ch
Adult neural stem cells (NSCs) are perceived as a homogeneous population of cells that divide infrequently and are capable of multi-lineage differentiation. However, recent data revealed that independent stem cell lineages act in parallel to maintain neurogenesis and provide a cellular source for tissue repair. In addition, even within the same lineage, the stem and progenitor cells are strikingly heterogeneous including NSCs that are dormant or mitotically active. We will discuss these different NSC populations and activity states with relation to their role in neurogenesis and regeneration but also how these different stem cells respond to aging. NSCs depend on Notch signaling for their maintenance. While Notch-dependence is a common feature among NSC populations, we will discuss how differences in Notch signaling might contribute to adult NSC heterogeneity. Understanding the fate of multiple NSC populations with distinct functions has implications for the mechanisms of aging and regeneration.

\section{INTRODUCTION}

Neural stem cells (NSCs) remain neurogenic during postnatal life within two regions of the mammalian brain, the subgranular zone (SGZ) of the hippocampal dentate gyrus (DG) and the subventricular zone (SVZ) of the wall of the lateral ventricles. The discovery of adult neurogenesis in mammals opened new avenues for research in regenerative medicine, with a goal of manipulating endogenous NSCs for brain repair (Gage and Temple, 2013). Over the last twenty years we have made considerable progress in our understanding of adult neurogenesis in homeostasis and disease (Ming and Song, 2011). However, several gaps remain in our knowledge that have to be filled before the potential of adult NSCs for regeneration can be fully exploited.

One such gap, and a field of active research, relates to the presence of heterogeneous subpopulations of NSCs within the same neurogenic niche (Alvarez-Buylla et al., 2008; Bonaguidi et al., 2012). The properties, functions, and lineage relationships between these subpopulations are still ill defined. Notch signaling is one molecular pathway involved in the regulation of NSC maintenance, proliferation, quiescence, and cell fate decisions. We propose that Notch signaling strength and diversity of downstream targets might, in concert with other molecular pathways, niche signals, and intrinsic factors, contribute to establishing adult NSC heterogeneity.

\section{THE ADULT NEUROGENIC LINEAGE IN SHORT}

Work from the 90's and early 2000's discovered the sequential developmental stages that cells undergo during lineage progression within the adult neurogenic niches (Alvarez-Buylla et al., 2001; Kempermann et al., 2004). Adult NSCs share ultrastructural and antigenic features with astrocytes (Kriegstein and AlvarezBuylla, 2009). Most adult NSCs are quiescent or intermittently dividing, which explains their resistance to antimitotic drug and high dose tritiated-thymidine treatment (Morshead et al., 1994; Doetsch et al., 1999; Seri et al., 2001). In the SVZ, NSCs that proliferate likely undergo asymmetric cell divisions to self-renew and generate committed intermediate progenitors (IPs). These mitotically active IPs generate neuroblasts that migrate to the olfactory bulb $(\mathrm{OB})$ where they mature into multiple types of neurons (Alvarez-Buylla et al., 2008). In the SGZ, NSCs also generate IPs that pass through a series of maturation stages before they differentiate into neuroblasts and subsequently granule neurons of the DG. This early work already implied some degree of heterogeneity in adult NSC and IP populations (Kempermann et al., 2004), suggesting that progression through the neurogenic lineage may be a more complex process than the simple NSC to IP to neuroblast transition. Later work added new insights into this emerging complexity and even proposed the coexistence of independent stem cell lineages acting in parallel.

\section{ADULT NEURAL STEM AND PROGENITOR CELL HETEROGENEITY WITHIN THE SAME LINEAGE}

The ability of adult NSCs to survive antimitotic drug treatment and regenerate the neurogenic lineage suggested that they rarely divide (Doetsch et al., 1999; Seri et al., 2001). This relative quiescence of NSCs is potentially linked to their potential for longterm maintenance over the lifespan of an organism (Kippin et al., 2005; Porlan et al., 2013). Indeed, quiescence of adult NSCs is actively promoted through several mechanisms including BMP and Notch signaling (Imayoshi et al., 2010; Mira et al., 2010), neurotransmitters (Berg et al., 2013), cell adhesion molecules (Kokovay et al., 2012), cell-cycle inhibitors (Kippin et al., 2005), and intrinsic factors (Martynoga et al., 2013). However, quiescence is not a prerequisite for somatic stem cell identity, and proliferating stem cell exist alongside more quiescent stem cell pools in several organs (Li and Clevers, 2010). A similar situation 
of dual stem cell populations may also exist in the neurogenic niches of the adult mammalian brain. A small but detectable fraction of adult NSCs proliferate quite rapidly in both the SVZ and SGZ (Encinas et al., 2011; Ponti et al., 2013). Even though NSCs can shuttle between active and quiescent states (Lugert et al., 2010; Bonaguidi et al., 2011), not all NSCs that proliferate re-enter a quiescent state, but some divide repeatedly (Lugert et al., 2010; Encinas et al., 2011; Ponti et al., 2013). Similarly, although quiescent NSCs enter cell-cycle to generate active NSCs (Bonaguidi et al., 2011; Encinas et al., 2011) and their exit from the quiescent state is augmented in response to neurogenic stimuli and during regeneration (Morshead et al., 1994; Doetsch et al., 1999; Lugert et al., 2010; Lopez-Juarez et al., 2013), it remains unclear what proportion of NSCs can be activated during homeostatic neurogenesis. Thus, it is possible that active and quiescent NSCs represent distinct pools where transition between the two is limited and tightly controlled, at least in the absence of injury, rather than all adult NSCs being equal in their ability to switch from quiescence to activity and back.

Discrimination of quiescent from activated NSC populations and niche astrocytes has proven difficult, but progress has been made toward this end in recent years (Pastrana et al., 2009; Beckervordersandforth et al., 2010; Mira et al., 2010; Ferron et al., 2011). Active NSCs within the SVZ express the epidermal growth factor receptor, respond to EGF with increased proliferation, and are eliminated by antimitotic drug treatment, similar to IPs, but retain expression of astrocytic and radial glia markers (Pastrana et al., 2009; Giachino et al., 2014). In the adult DG, a nonradial morphology correlates with the active state (Suh et al., 2007; Lugert et al., 2010), but molecular markers that demarcate quiescent and active NSC populations have still to be defined. Interestingly, genetic lineage tracing using promoters that potentially over-represent either quiescent or active cells suggest differences in the contribution of these populations to long-term neurogenesis (DeCarolis et al., 2013). Identifying markers that discriminate between NSCs with distinct proliferative activities is needed to develop genetic tools for independent and simultaneous lineage tracing of active and quiescent NSC pools, and determine their respective lifespan and inter-conversion in vivo. Lineage tracing approaches with inducible-cre/flp technologies and intersectional analyses combining promoters of cell-cycle marker genes with NSC marker genes may be useful to this end.

Heterogeneity in the adult neurogenic lineage is not restricted to NSCs. In the SVZ, a proportion of Ascl1+ IPs expresses radial glia markers whereas others do not (Pastrana et al., 2009; Giachino et al., 2014). In the SGZ, a combination of Nestin, Ascl1, Tbr2, and Doublecortin expression defines at least three stages of committed progenitors (Kempermann et al., 2004; Hodge et al., 2008). It is still unclear if marker heterogeneity of IPs reflects differences in their self-renewal abilities, but it is interesting that differences in cell-cycle dynamics of IP populations in the SVZ have been recently reported (Ponti et al., 2013). Moreover, late IPs and neuroblasts make up a large fraction of proliferating cells in both neurogenic niches (Hodge et al., 2008; Lugert et al., 2012; Ponti et al., 2013), proposing that substantial lineage amplification occurs right before cell-cycle exit and terminal differentiation.

\section{HETEROGENEOUS NSC LINEAGES ACTING IN PARALLEL}

Adult NSCs are capable of multi-lineage differentiation and able to clonally generate multiple neural lineages under appropriate conditions in vitro (Suh et al., 2007; Pastrana et al., 2011). Moreover, they show some degree of lineage plasticity upon heterotopic or heterochronic transplantation into neurogenic niches distinct to their origin (Suhonen et al., 1996; Sequerra et al., 2010). Indeed, elegant lineage tracing experiments demonstrated that DG NSCs are bi-potent at the single cell level and self-renew in vivo (Suh et al., 2007; Bonaguidi et al., 2011). SVZ NSCs are able to generate neurons, astrocytes and oligodendrocytes at the population level in vivo (Alvarez-Buylla et al., 2001; Menn et al., 2006; Benner et al., 2013). However, and apparently in contrast to these findings, other fate-mapping and transplantation studies demonstrated that SVZ NSCs are heterogeneous and their spatial distribution correlates with cell fate (Kelsch et al., 2007; Merkle et al., 2007). NSCs show a preference toward the production of distinct types of neurons depending on their dorsal-ventral position within the adult SVZ, and this differentiation bias seems to be intrinsic as it is maintained after in vitro passage and heterotopic transplantation (Merkle et al., 2007). In the same line, NSCs cultured in the absence of growth factors are able to generate either neurons or oligodendrocytes, in addition to astrocytes, but not both neurons and oligodendrocytes within the same lineage tree (Ortega et al., 2013). NSCs with oligodendrocytic potential are enriched in the dorsal and anterior SVZ (Gritti et al., 2002; Ortega et al., 2013). Genetic fate mapping indicates that these heterogeneous NSC populations in the adult SVZ are remnants of distinct germinative niches of the embryonic forebrain and derive from Emx1, Dbx1, Gsh2, Nkx2.1 or Nkx6.2 expressing lineages (Kohwi et al., 2007; Ventura and Goldman, 2007; Young et al., 2007; Lopez-Juarez et al., 2013; Merkle et al., 2014). These data suggest that the SVZ is arranged as a mosaic that is established during embryogenesis and the location within the niche can predict the type of progeny that NSCs give rise to. Whether this heterogeneity of lineages is intrinsically determined or regulated by extrinsic cues at distinct locations within the niche, or a combination of both, is still a matter of debate (Sequerra et al., 2013). The fact that manipulation of morphogen signals skews NSC differentiation potential in vivo suggest that the local environment plays a role in regional specification of adult NSCs (Ihrie et al., 2011). Moreover, pathological conditions stimulate NSCs to produce progenies that are different from the ones generated during homeostasis and these can migrate toward non-canonical locations, suggesting that cell fate is not fixed (Kernie and Parent, 2010; Ohira, 2011). Defining the degree of lineage plasticity of adult NSCs and the signals that can override their intrinsic programming has important implications for developing cell replacement strategies based on the mobilization of endogenous cells.

\section{CONTRIBUTION OF NOTCH SIGNALING TO HETEROGENEITY OF THE ADULT NSC POOL}

Notch signaling is a key mediator of NSC maintenance in the developing and adult brains (Ables et al., 2011; Pierfelice et al., 2011). Notchs are transmembrane receptors and undergo a series of proteolytic cleavages that liberate the Notch intracellular domain (NICD) upon binding to their ligands. The canonical 
Notch signal links the NICD to the nuclear CSL (RBP-J in mice) transcriptional complex (Mumm and Kopan, 2000). The activity of Notch target genes of the Hes/Hey family is fundamental for maintaining NSCs in an undifferentiated state, suppressing the expression of proneural genes including Ascll (Louvi and Artavanis-Tsakonas, 2006). Inhibition of Notch or RBP-J in adult NSCs results in NSC loss and impaired neurogenesis (Breunig et al., 2007; Andreu-Agullo et al., 2009; Ables et al., 2010; Aguirre et al., 2010; Chapouton et al., 2010; Ehm et al., 2010; Imayoshi et al., 2010; Lugert et al., 2010; Imayoshi and Kageyama, 2011). Canonical Notch signaling activity and Hes5 expression in particular distinguish NSCs from IPs in the developing and adult brain (Basak and Taylor, 2007; Mizutani et al., 2007; Andreu-Agullo et al., 2009; Imayoshi et al., 2010; Lugert et al., 2010; Giachino et al., 2014). It is unclear if Notch signaling contributes to adult NSC heterogeneity, but studies revealing that impairing distinct Notch pathway components affects distinct stages of the neurogenic lineage suggest that this might be the case. Notch 1 promotes adult NSC proliferation whilst maintaining the undifferentiated state, proposing a role of the pathway in the maintenance of the active NSC subpopulation (Nyfeler et al., 2005; AndroutsellisTheotokis et al., 2006; Breunig et al., 2007; Ables et al., 2010; Aguirre et al., 2010; Basak et al., 2012). In contrast, activation of the RBP-J mediated canonical Notch pathway, potentially promoted by Dll1 ligand expressed by proliferating NSCs and IPs, preserves the quiescent NSC pool (Carlen et al., 2009; Ehm et al., 2010; Imayoshi et al., 2010; Basak et al., 2012; Kawaguchi et al., 2013). These data suggest that Notch can differentially regulate active and quiescent NSC populations in a context-dependent manner. Given that Hes5 is expressed in both dividing and dormant adult NSCs, Notch is unlikely to be the only key to NSC heterogeneity (Lugert et al., 2010; Giachino et al., 2014). However, differences in the strength, dynamics, and targets of the pathway may contribute to heterogeneity and explain the discrepancies observed in mouse mutant phenotypes. Low levels of Notch activation (NICD) for instance promote proliferation of embryonic neural progenitors, whereas high levels lead to growth arrest in vitro (Guentchev and McKay, 2006). Therefore, one possibility is that the differential actions of Notch on proliferation vs. quiescence of adult NSCs are a function of dose. Another possibility is that oscillatory vs. sustained expression of Notch targets differentiate active and quiescent NSC pools. In mouse embryonic NSCs and progenitors, levels of Hes1/Hes5 oscillate in anti-phase with their repressed target Ascl1, and this oscillatory expression promotes proliferation (Imayoshi et al., 2013). In contrast, sustained Hes1 expression inhibits NSC proliferation and neurogenesis in the developing central nervous system (Baek et al., 2006). It is currently not known if the expression of Hes genes is sustained or oscillatory in adult NSCs, and the available tools are not adequate to address this issue in vivo. However, oscillatory expression of Notch targets together with low refractory expression of Ascl1 in adult NSCs that are in the cell-cycle would be compatible with data showing that the Ascl1::CreER locus can be used to lineage trace a subpopulation of neurogenic NSCs in vivo (Kim et al., 2011). Conversely, quiescent adult NSCs express high levels of Id proteins (Nam and Benezra, 2009), which can interfere with the negative autoregulation of Hes 1 and therefore modulate its oscillatory expression (Bai et al., 2007). These findings prompt to speculate that Hes genes are persistently expressed at high levels in quiescent NSCs.

Another possible scenario to explain the multifaceted functions of Notch in adult NSCs would be that distinct pathway components are differentially engaged in Notch signaling activity in different cell subpopulations. It has been proposed that Notch1 is required to maintain the active adult NSC pool but is dispensable during quiescence (Ables et al., 2010; Basak et al., 2012). This suggests that other members of the Notch family could provide a maintenance signal for quiescent NSCs and compensate for the absence of Notch1 in this population (Basak et al., 2012). Heterogeneity of Notch activity is related to cellular diversity in the neurogenic niches of the adult zebrafish brain, where Notch3 gates NSC activation whereas Notch1b maintains activated progenitors (Alunni et al., 2013). Interestingly, Notch3 restricts stem cell activation in muscle and mammary, while Notch1 is associated with proliferation (Carlson et al., 2008; Kitamoto and Hanaoka, 2010; Bjornson et al., 2012; Mourikis et al., 2012; Lafkas et al., 2013). It is tempting to speculate that distinct Notch receptors differentially regulate quiescent and active stem cell subpopulations in the adult mammalian brain. In addition to NSC heterogeneity within the same lineage, independent NSC lineages are fated to generate distinct OB neurons in the SVZ. Lineage tracing experiments with Hes5::CreER transgenic mice demonstrated that NSCs with active canonical Notch signaling generate multiple neuron subtypes in the OB (Giachino et al., 2014) implying that all adult NSC lineages require Notch for maintenance. However, this does not exclude that different receptors or receptor combinations mediate Notch activity within the NSCs of each lineage. Interestingly, genetic fate mapping of cells expressing individual Notchs revealed multiple lineages in bone marrow and mammary gland (Lafkas et al., 2013; Oh et al., 2013; Sale et al., 2013).

Not only the activity of Notch paralogues, but also combinations of different Notch target genes in NSC subpopulations may be a source of heterogeneity. NSCs in the developing neural tube of the mouse are heterogeneous based on their expression of Hes family genes, with cohorts of radial glia cells expressing either Hes1 or Hes5, or both (Basak and Taylor, 2007; Nelson et al., 2013). Brain lipid binding protein (BLBP), a direct target of Notch signaling (Anthony et al., 2005), is also expressed heterogeneously by radial glia (Hartfuss et al., 2001). Recently, it was shown that different combinations of Her/Hes family genes correlate with the proliferation rate of NSCs and progenitors in the adult zebrafish (Chapouton et al., 2011). In the same line, BLBP expression positively correlates with proliferation of Hes5-expressing NSCs in the adult mouse SVZ, whereas most quiescent NSCs express Hes5 but not BLBP (Giachino et al., 2014). How combinatorial or selective expression of Notch targets regulates the fate and activity of adult NSC subpopulations deserves closer scrutiny in the future.

\section{IMPLICATIONS OF ADULT NSC HETEROGENEITY FOR AGING AND REGENERATION}

The adult mammalian neurogenic niches show a remarkable capacity for self-repair and remodeling in response to lesion (Doetsch et al., 1999; Seri et al., 2001; Kuo et al., 2006; Nomura et al., 2010). However, neurogenesis declines with age in both 
the SVZ and SGZ (Lazarov et al., 2010) and most neuron subtypes produced in the OB are equally affected (Shook et al., 2012). Understanding the basis of this overall age-related decline in neurogenesis, and the mechanisms controlling self-renewal over the life on an individual, is fundamental to exploit the regenerative potential of adult NSCs.

One cause of reduced neurogenesis during aging is the impairment of the NSC compartment. An open question is whether this impairment reflects depletion or increased quiescence of NSCs (Hattiangady and Shetty, 2008; Lugert et al., 2010; Encinas et al., 2011; Shook et al., 2012; Giachino et al., 2014). This issue remains debated as most studies did not take into account the differential effects that aging may have on NSC subpopulations. One possibility is that active NSCs are more susceptible to imbalances between maintenance and differentiation signals that may occur during aging. These imbalances affect self-renewal, and therefore active NSCs are preferentially lost compared to quiescent populations (Lugert et al., 2010; Encinas et al., 2011; Giachino et al., 2014). Furthermore, some quiescent NSCs may activate to replenish an exhausted active NSC pool and thereby also be lost during aging. This is supported by findings that quiescent NSCs are reduced with time following depletion of the active NSC pool either by genetic means (Basak et al., 2012), or chronic treatment with antimitotic drugs (Doetsch et al., 1999). However, a variable but substantial proportion of NSCs is preserved in both the SGZ and SVZ of old mice, but these are dormant rather than senescent and can be reactivated (Jin et al., 2003; Hattiangady and Shetty, 2008; Lugert et al., 2010; Giachino et al., 2014). It will be important to genetically trace the progeny of distinct NSC populations during aging to assess differences in their lifespan, lineage plasticity and regenerative potential. Understanding the mechanisms responsible for NSC dormancy in the mouse neurogenic niches could help to understand why most NSCs in the human brain stop generating neurons after birth (Sanai et al., 2011).

\section{REFERENCES}

Ables, J. L., Breunig, J. J., Eisch, A. J., and Rakic, P. (2011). Not(ch) just development: notch signalling in the adult brain. Nat. Rev. Neurosci. 12, 269-283. doi: $10.1038 / \mathrm{nrn} 3024$

Ables, J. L., Decarolis, N. A., Johnson, M. A., Rivera, P. D., Gao, Z., Cooper, D. C., et al. (2010). Notch1 is required for maintenance of the reservoir of adult hippocampal stem cells. J. Neurosci. 30, 10484-10492. doi: 10.1523/JNEUROSCI.4721-09.2010

Aguirre, A., Rubio, M. E., and Gallo, V. (2010). Notch and EGFR pathway interaction regulates neural stem cell number and self-renewal. Nature 467, 323-327. doi: 10.1038/nature09347

Alunni, A., Krecsmarik, M., Bosco, A., Galant, S., Pan, L., Moens, C. B., et al. (2013). Notch3 signaling gates cell cycle entry and limits neural stem cell amplification in the adult pallium. Development 140, 3335-3347. doi: 10.1242/dev.095018

Alvarez-Buylla, A., Garcia-Verdugo, J. M., and Tramontin, A. D. (2001). A unified hypothesis on the lineage of neural stem cells. Nat. Rev. Neurosci. 2, 287-293. doi: 10.1038/35067582

Alvarez-Buylla, A., Kohwi, M., Nguyen, T. M., and Merkle, F. T. (2008). The heterogeneity of adult neural stem cells and the emerging complexity of their niche. Cold Spring Harb. Symp. Quant. Biol. 73, 357-365. doi: 10.1101/sqb.2008.73.019

Andreu-Agullo, C., Morante-Redolat, J. M., Delgado, A. C., and Farinas, I. (2009). Vascular niche factor PEDF modulates Notch-dependent stemness in the adult subependymal zone. Nat. Neurosci. 12, 1514-1523. doi: 10.1038/nn.2437

Androutsellis-Theotokis, A., Leker, R. R., Soldner, F., Hoeppner, D. J., Ravin, R., Poser, S. W., et al. (2006). Notch signalling regulates stem cell numbers in vitro and in vivo. Nature 442, 823-826. doi: 10.1038/nature04940
Anthony, T. E., Mason, H. A., Gridley, T., Fishell, G., and Heintz, N. (2005). Brain lipid-binding protein is a direct target of Notch signaling in radial glial cells. Genes Dev. 19, 1028-1033. doi: 10.1101/gad.1302105

Baek, J. H., Hatakeyama, J., Sakamoto, S., Ohtsuka, T., and Kageyama, R. (2006). Persistent and high levels of Hesl expression regulate boundary formation in the developing central nervous system. Development 133, 2467-2476. doi: $10.1242 / \mathrm{dev} .02403$

Bai, G., Sheng, N., Xie, Z., Bian, W., Yokota, Y., Benezra, R., et al. (2007). Id sustains Hes1 expression to inhibit precocious neurogenesis by releasing negative autoregulation of Hes1. Dev. Cell 13, 283-297. doi: 10.1016/j.devcel. 2007.05.014

Basak, O., Giachino, C., Fiorini, E., Macdonald, H. R., and Taylor, V. (2012). Neurogenic subventricular zone stem/progenitor cells are Notch1-dependent in their active but not quiescent state. J. Neurosci. 32, 5654-5666. doi: 10.1523/JNEUROSCI.0455-12.2012

Basak, O., and Taylor, V. (2007). Identification of self-replicating multipotent progenitors in the embryonic nervous system by high Notch activity and Hes5 expression. Eur. J. Neurosci. 25, 1006-1022. doi: 10.1111/j.14609568.2007.05370.x

Beckervordersandforth, R., Tripathi, P., Ninkovic, J., Bayam, E., Lepier, A., Stempfhuber, B., et al. (2010). In vivo fate mapping and expression analysis reveals molecular hallmarks of prospectively isolated adult neural stem cells. Cell Stem Cell 7, 744-758. doi: 10.1016/j.stem.2010.11.017

Benner, E. J., Luciano, D., Jo, R., Abdi, K., Paez-Gonzalez, P., Sheng, H., et al. (2013). Protective astrogenesis from the SVZ niche after injury is controlled by Notch modulator Thbs4. Nature 497, 369-373. doi: 10.1038/nature12069

Berg, D. A., Belnoue, L., Song, H., and Simon, A. (2013). Neurotransmittermediated control of neurogenesis in the adult vertebrate brain. Development 140, 2548-2561. doi: 10.1242/dev.088005

Bjornson, C. R., Cheung, T. H., Liu, L., Tripathi, P. V., Steeper, K. M., and Rando, T. A. (2012). Notch signaling is necessary to maintain quiescence in adult muscle stem cells. Stem Cells 30, 232-242. doi: 10.1002/stem.773

Bonaguidi, M. A., Song, J., Ming, G. L., and Song, H. (2012). A unifying hypothesis on mammalian neural stem cell properties in the adult hippocampus. Curr. Opin. Neurobiol. 22, 754-761. doi: 10.1016/j.conb.2012.03.013

Bonaguidi, M. A., Wheeler, M. A., Shapiro, J. S., Stadel, R. P., Sun, G. J., Ming, G. L., et al. (2011). In vivo clonal analysis reveals self-renewing and multipotent adult neural stem cell characteristics. Cell 145, 1142-1155. doi: 10.1016/j.cell.2011.05.024

Breunig, J. J., Silbereis, J., Vaccarino, F. M., Sestan, N., and Rakic, P. (2007). Notch regulates cell fate and dendrite morphology of newborn neurons in the postnatal dentate gyrus. Proc. Natl. Acad. Sci. U.S.A. 104, 20558-20563. doi: $10.1073 /$ pnas. 0710156104

Carlen, M., Meletis, K., Goritz, C., Darsalia, V., Evergren, E., Tanigaki, K., et al. (2009). Forebrain ependymal cells are Notch-dependent and generate neuroblasts and astrocytes after stroke. Nat. Neurosci. 12, 259-267. doi: $10.1038 / \mathrm{nn} .2268$

Carlson, M. E., Hsu, M., and Conboy, I. M. (2008). Imbalance between pSmad3 and Notch induces CDK inhibitors in old muscle stem cells. Nature 454, 528-532. doi: 10.1038/nature07034

Chapouton, P., Skupien, P., Hesl, B., Coolen, M., Moore, J. C., Madelaine, R., et al. (2010). Notch activity levels control the balance between quiescence and recruitment of adult neural stem cells. J. Neurosci. 30, 7961-7974. doi: 10.1523/JNEUROSCI.6170-09.2010

Chapouton, P., Webb, K. J., Stigloher, C., Alunni, A., Adolf, B., Hesl, B., et al. (2011). Expression of hairy/enhancer of split genes in neural progenitors and neurogenesis domains of the adult zebrafish brain. J. Comp. Neurol. 519, 1748-1769. doi: $10.1002 / \mathrm{cne} .22599$

DeCarolis, N. A., Mechanic, M., Petrik, D., Carlton, A., Ables, J. L., Malhotra, S., et al. (2013). In vivo contribution of nestin- and GLAST-lineage cells to adult hippocampal neurogenesis. Hippocampus 23, 708-719. doi: 10.1002/ hipo. 22130

Doetsch, F., Garcia-Verdugo, J. M., and Alvarez-Buylla, A. (1999). Regeneration of a germinal layer in the adult mammalian brain. Proc. Natl. Acad. Sci. U.S.A. 96, 11619-11624. doi: 10.1073/pnas.96.20.11619

Ehm, O., Goritz, C., Covic, M., Schaffner, I., Schwarz, T. J., Karaca, E., et al. (2010). RBPJkappa-dependent signaling is essential for long-term maintenance of neural stem cells in the adult hippocampus. J. Neurosci. 30, 13794-13807. doi: 10.1523/JNEUROSCI.1567-10.2010 
Encinas, J. M., Michurina, T. V., Peunova, N., Park, J. H., Tordo, J., Peterson, D. A., et al. (2011). Division-coupled astrocytic differentiation and age-related depletion of neural stem cells in the adult hippocampus. Cell Stem Cell 8, 566-579. doi: 10.1016/j.stem.2011.03.010

Ferron, S. R., Charalambous, M., Radford, E., McEwen, K., Wildner, H., Hind, E., et al. (2011). Postnatal loss of Dlk1 imprinting in stem cells and niche astrocytes regulates neurogenesis. Nature 475, 381-385. doi: 10.1038/nature10229

Gage, F. H., and Temple, S. (2013). Neural stem cells: generating and regenerating the brain. Neuron 80, 588-601. doi: 10.1016/j.neuron.2013.10.037

Giachino, C., Basak, O., Lugert, S., Knuckles, P., Obernier, K., Fiorelli, R., et al. (2014). Molecular diversity subdivides the adult forebrain neural stem cell population. Stem Cells 32, 70-84. doi: 10.1002/stem.1520

Gritti, A., Bonfanti, L., Doetsch, F., Caille, I., Alvarez-Buylla, A., Lim, D. A., et al. (2002). Multipotent neural stem cells reside into the rostral extension and olfactory bulb of adult rodents. J. Neurosci. 22, 437-445.

Guentchev, M., and McKay, R. D. (2006). Notch controls proliferation and differentiation of stem cells in a dose-dependent manner. Eur. J. Neurosci. 23, 2289-2296. doi: 10.1111/j.1460-9568.2006.04766.x

Hartfuss, E., Galli, R., Heins, N., and Gotz, M. (2001). Characterization of CNS precursor subtypes and radial glia. Dev. Biol. 229, 15-30. doi: 10.1006/dbio.2000.9962

Hattiangady, B., and Shetty, A. K. (2008). Aging does not alter the number or phenotype of putative stem/progenitor cells in the neurogenic region of the hippocampus. Neurobiol. Aging 29, 129-147. doi: 10.1016/j.neurobiolaging.2006.09.015

Hodge, R. D., Kowalczyk, T. D., Wolf, S. A., Encinas, J. M., Rippey, C., Enikolopov, G., et al. (2008). Intermediate progenitors in adult hippocampal neurogenesis: Tbr2 expression and coordinate regulation of neuronal output. J. Neurosci. 28, 3707-3717. doi: 10.1523/JNEUROSCI.4280-07.2008

Ihrie, R. A., Shah, J. K., Harwell, C. C., Levine, J. H., Guinto, C. D., Lezameta, M., et al. (2011). Persistent sonic hedgehog signaling in adult brain determines neural stem cell positional identity. Neuron 71, 250-262. doi: 10.1016/j.neuron.2011.05.018

Imayoshi, I., Isomura, A., Harima, Y., Kawaguchi, K., Kori, H., Miyachi, H., et al. (2013). Oscillatory control of factors determining multipotency and fate in mouse neural progenitors. Science 342, 1203-1208. doi: 10.1126/science. 1242366

Imayoshi, I., and Kageyama, R. (2011). The role of Notch signaling in adult neurogenesis. Mol. Neurobiol. 44, 7-12. doi: 10.1007/s12035-011-8186-0

Imayoshi, I., Sakamoto, M., Yamaguchi, M., Mori, K., and Kageyama, R. (2010). Essential roles of Notch signaling in maintenance of neural stem cells in developing and adult brains. J. Neurosci. 30, 3489-3498. doi: 10.1523/JNEUROSCI.4987-09.2010

Jin, K., Sun, Y., Xie, L., Batteur, S., Mao, X. O., Smelick, C., et al. (2003). Neurogenesis and aging: FGF-2 and HB-EGF restore neurogenesis in hippocampus and subventricular zone of aged mice. Aging Cell 2, 175-183. doi: 10.1046/j.1474-9728.2003.00046.x

Kawaguchi, D., Furutachi, S., Kawai, H., Hozumi, K., and Gotoh, Y. (2013). Dll1 maintains quiescence of adult neural stem cells and segregates asymmetrically during mitosis. Nat. Commun. 4, 1880. doi: 10.1038/ncomms 2895

Kelsch, W., Mosley, C. P., Lin, C. W., and Lois, C. (2007). Distinct mammalian precursors are committed to generate neurons with defined dendritic projection patterns. PLoS Biol. 5:e300. doi: 10.1371/journal.pbio.0050300

Kempermann, G., Jessberger, S., Steiner, B., and Kronenberg, G. (2004). Milestones of neuronal development in the adult hippocampus. Trends Neurosci. 27, 447-452. doi: 10.1016/j.tins.2004.05.013

Kernie, S. G., and Parent, J. M. (2010). Forebrain neurogenesis after focal Ischemic and traumatic brain injury. Neurobiol. Dis. 37, 267-274. doi: 10.1016/j.nbd.2009.11.002

Kim, E. J., Ables, J. L., Dickel, L. K., Eisch, A. J., and Johnson, J. E. (2011) Ascl1 (Mash1) defines cells with long-term neurogenic potential in subgranular and subventricular zones in adult mouse brain. PLOS ONE 6:e18472. doi: 10.1371/journal.pone.0018472

Kippin, T. E., Martens, D. J., and van der Kooy, D. (2005). p21 loss compromises the relative quiescence of forebrain stem cell proliferation leading to exhaustion of their proliferation capacity. Genes Dev. 19, 756-767. doi: 10.1101/gad.1272305

Kitamoto, T., and Hanaoka, K. (2010). Notch3 null mutation in mice causes muscle hyperplasia by repetitive muscle regeneration. Stem Cells 28, 2205-2216. doi: $10.1002 /$ stem. 547
Kohwi, M., Petryniak, M. A., Long, J. E., Ekker, M., Obata, K., Yanagawa, Y., et al. (2007). A subpopulation of olfactory bulb GABAergic interneurons is derived from Emx1- and Dlx5/6-expressing progenitors. J. Neurosci. 27, 6878-6891. doi: 10.1523/JNEUROSCI.0254-07.2007

Kokovay, E., Wang, Y., Kusek, G., Wurster, R., Lederman, P., Lowry, N., et al. (2012). VCAM1 is essential to maintain the structure of the SVZ niche and acts as an environmental sensor to regulate SVZ lineage progression. Cell Stem Cell 11, 220-230. doi: 10.1016/j.stem.2012.06.016

Kriegstein, A., and Alvarez-Buylla, A. (2009). The glial nature of embryonic and adult neural stem cells. Annu. Rev. Neurosci. 32, 149-184. doi: 10.1146/annurev.neuro.051508.135600

Kuo, C. T., Mirzadeh, Z., Soriano-Navarro, M., Rasin, M., Wang, D., Shen, J., et al. (2006). Postnatal deletion of Numb/Numblike reveals repair and remodeling capacity in the subventricular neurogenic niche. Cell 127, 1253-1264. doi: 10.1016/j.cell.2006.10.041

Lafkas, D., Rodilla, V., Huyghe, M., Mourao, L., Kiaris, H., and Fre, S. (2013). Notch3 marks clonogenic mammary luminal progenitor cells in vivo. J. Cell Biol. 203, 47-56. doi: 10.1083/jcb.201307046

Lazarov, O., Mattson, M. P., Peterson, D. A., Pimplikar, S. W., and van Praag, H. (2010). When neurogenesis encounters aging and disease. Trends Neurosci. 33, 569-579. doi: 10.1016/j.tins.2010.09.003

Li, L., and Clevers, H. (2010). Coexistence of quiescent and active adult stem cells in mammals. Science 327, 542-545. doi: 10.1126/science.1180794

Lopez-Juarez, A., Howard, J., Ullom, K., Howard, L., Grande, A., Pardo, A., et al. (2013). Gsx2 controls region-specific activation of neural stem cells and injury-induced neurogenesis in the adult subventricular zone. Genes Dev. 27, 1272-1287. doi: 10.1101/gad.217539.113

Louvi, A., and Artavanis-Tsakonas, S. (2006). Notch signalling in vertebrate neural development. Nat. Rev. Neurosci. 7, 93-102. doi: 10.1038/nrn1847

Lugert, S., Basak, O., Knuckles, P., Haussler, U., Fabel, K., Gotz, M., et al. (2010). Quiescent and active hippocampal neural stem cells with distinct morphologies respond selectively to physiological and pathological stimuli and aging. Cell Stem Cell 6, 445-456. doi: 10.1016/j.stem.2010.03.017

Lugert, S., Vogt, M., Tchorz, J. S., Muller, M., Giachino, C., and Taylor, V. (2012). Homeostatic neurogenesis in the adult hippocampus does not involve amplification of Ascl1(high) intermediate progenitors. Nat. Commun. 3, 670. doi: $10.1038 /$ ncomms 1670

Martynoga, B., Mateo, J. L., Zhou, B., Andersen, J., Achimastou, A., Urban, N., et al. (2013). Epigenomic enhancer annotation reveals a key role for NFIX in neural stem cell quiescence. Genes Dev. 27, 1769-1786. doi: 10.1101/gad.216804.113

Menn, B., Garcia-Verdugo, J. M., Yaschine, C., Gonzalez-Perez, O., Rowitch, D., and Alvarez-Buylla, A. (2006). Origin of oligodendrocytes in the subventricular zone of the adult brain. J. Neurosci. 26, 7907-7918. doi: 10.1523/JNEUROSCI.129906.2006

Merkle, F. T., Fuentealba, L. C., Sanders, T. A., Magno, L., Kessaris, N., and Alvarez-Buylla, A. (2014). Adult neural stem cells in distinct microdomains generate previously unknown interneuron types. Nat. Neurosci. 17, 207-214. doi: 10.1038/nn.3610

Merkle, F. T., Mirzadeh, Z., and Alvarez-Buylla, A. (2007). Mosaic organization of neural stem cells in the adult brain. Science 317, 381-384. doi: 10.1126/science. 1144914

Ming, G. L., and Song, H. (2011). Adult neurogenesis in the mammalian brain: significant answers and significant questions. Neuron 70, 687-702. doi: 10.1016/j.neuron.2011.05.001

Mira, H., Andreu, Z., Suh, H., Lie, D. C., Jessberger, S., Consiglio, A., et al. (2010). Signaling through BMPR-IA regulates quiescence and long-term activity of neural stem cells in the adult hippocampus. Cell Stem Cell 7, 78-89. doi: 10.1016/j.stem.2010.04.016

Mizutani, K., Yoon, K., Dang, L., Tokunaga, A., and Gaiano, N. (2007). Differential Notch signalling distinguishes neural stem cells from intermediate progenitors. Nature 449, 351-355. doi: 10.1038/nature06090

Morshead, C. M., Reynolds, B. A., Craig, C. G., McBurney, M. W., Staines, W. A., Morassutti, D., et al. (1994). Neural stem cells in the adult mammalian forebrain: a relatively quiescent subpopulation of subependymal cells. Neuron 13, 1071-1082. doi: 10.1016/0896-6273(94)90046-9

Mourikis, P., Sambasivan, R., Castel, D., Rocheteau, P., Bizzarro, V., and Tajbakhsh, S. (2012). A critical requirement for notch signaling in maintenance of the quiescent skeletal muscle stem cell state. Stem Cells 30, 243-252. doi: $10.1002 /$ stem.775 
Mumm, J. S., and Kopan, R. (2000). Notch signaling: from the outside in. Dev. Biol. 228, 151-165. doi: 10.1006/dbio.2000.9960

Nam, H. S., and Benezra, R. (2009). High levels of Idl expression define B1 type adult neural stem cells. Cell Stem Cell 5, 515-526. doi: 10.1016/j.stem.2009.08.017

Nelson, B. R., Hodge, R. D., Bedogni, F., and Hevner, R. F. (2013). Dynamic interactions between intermediate neurogenic progenitors and radial glia in embryonic mouse neocortex: potential role in Dll1-Notch signaling. J. Neurosci. 33, 9122-9139. doi: 10.1523/JNEUROSCI.0791-13.2013

Nomura, T., Goritz, C., Catchpole, T., Henkemeyer, M., and Frisen, J. (2010). EphB signaling controls lineage plasticity of adult neural stem cell niche cells. Cell Stem Cell 7, 730-743. doi: 10.1016/j.stem.2010.11.009

Nyfeler, Y., Kirch, R. D., Mantei, N., Leone, D. P., Radtke, F., Suter, U., et al. (2005). Jagged 1 signals in the postnatal subventricular zone are required for neural stem cell self-renewal. EMBO J. 24, 3504-3515. doi: 10.1038/sj.emboj.7600816

Oh, P., Lobry, C., Gao, J., Tikhonova, A., Loizou, E., Manent, J., et al. (2013). In vivo mapping of notch pathway activity in normal and stress hematopoiesis. Cell Stem Cell 13, 190-204. doi: 10.1016/j.stem.2013.05.015

Ohira, K. (2011). Injury-induced neurogenesis in the mammalian forebrain. Cell. Mol. Life Sci. 68, 1645-1656. doi: 10.1007/s00018-010-0552-y

Ortega, F., Gascon, S., Masserdotti, G., Deshpande, A., Simon, C., Fischer, J., et al. (2013). Oligodendrogliogenic and neurogenic adult subependymal zone neural stem cells constitute distinct lineages and exhibit differential responsiveness to Wnt signalling. Nat. Cell Biol. 15, 602-613. doi: 10.1038/ncb2736

Pastrana, E., Cheng, L. C., and Doetsch, F. (2009). Simultaneous prospective purification of adult subventricular zone neural stem cells and their progeny. Proc. Natl. Acad. Sci. U.S.A. 106, 6387-6392. doi: 10.1073/pnas.0810407106

Pastrana, E., Silva-Vargas, V., and Doetsch, F. (2011). Eyes wide open: a critical review of sphere-formation as an assay for stem cells. Cell Stem Cell 8, 486-498. doi: 10.1016/j.stem.2011.04.007

Pierfelice, T., Alberi, L., and Gaiano, N. (2011). Notch in the vertebrate nervous system: an old dog with new tricks. Neuron 69, 840-855. doi: 10.1016/j.neuron.2011.02.031

Ponti, G., Obernier, K., Guinto, C., Jose, L., Bonfanti, L., and Alvarez-Buylla, A. (2013). Cell cycle and lineage progression of neural progenitors in the ventricular-subventricular zones of adult mice. Proc. Natl. Acad. Sci. U.S.A. 110, E1045-E1054. doi: 10.1073/pnas.1219563110

Porlan, E., Morante-Redolat, J. M., Marques-Torrejon, M. A., Andreu-Agullo, C., Carneiro, C., Gomez-Ibarlucea, E., et al. (2013). Transcriptional repression of Bmp2 by p21(Waf1/Cip1) links quiescence to neural stem cell maintenance. Nat. Neurosci. 16, 1567-1575. doi: 10.1038/nn.3545

Sale, S., Lafkas, D., and Artavanis-Tsakonas, S. (2013). Notch2 genetic fate mapping reveals two previously unrecognized mammary epithelial lineages. Nat. Cell Biol. 15, 451-460. doi: 10.1038/ncb2725

Sanai, N., Nguyen, T., Ihrie, R. A., Mirzadeh, Z., Tsai, H. H., Wong, M., et al. (2011). Corridors of migrating neurons in the human brain and their decline during infancy. Nature 478, 382-386. doi: 10.1038/nature10487
Sequerra, E. B., Costa, M. R., Menezes, J. R., and Hedin-Pereira, C. (2013). Adult neural stem cells: plastic or restricted neuronal fates? Development 140, 3303-3309. doi: 10.1242/dev.093096

Sequerra, E. B., Miyakoshi, L. M., Froes, M. M., Menezes, J. R., and Hedin-Pereira, C. (2010). Generation of glutamatergic neurons from postnatal and adult subventricular zone with pyramidallike morphology. Cereb. Cortex 20, 2583-2591. doi: 10.1093/cercor/ bhq006

Seri, B., Garcia-Verdugo, J. M., McEwen, B. S., and Alvarez-Buylla, A. (2001). Astrocytes give rise to new neurons in the adult mammalian hippocampus. J. Neurosci. 21, 7153-7160.

Shook, B. A., Manz, D. H., Peters, J. J., Kang, S., and Conover, J. C. (2012). Spatiotemporal changes to the subventricular zone stem cell pool through aging. J. Neurosci. 32, 6947-6956. doi: 10.1523/JNEUROSCI 5987-11.2012

Suh, H., Consiglio, A., Ray, J., Sawai, T., D’Amour, K. A., and Gage, F. H. (2007). In vivo fate analysis reveals the multipotent and self-renewal capacities of Sox $2+$ neural stem cells in the adult hippocampus. Cell Stem Cell 1, 515-528. doi: 10.1016/j.stem.2007. 09.002

Suhonen, J. O., Peterson, D. A., Ray, J., and Gage, F. H. (1996). Differentiation of adult hippocampus-derived progenitors into olfactory neurons in vivo. Nature 383, 624-627. doi: 10.1038/383624a0

Ventura, R. E., and Goldman, J. E. (2007). Dorsal radial glia generate olfactory bulb interneurons in the postnatal murine brain. J. Neurosci. 27, 4297-4302. doi: 10.1523/JNEUROSCI.0399-07.2007

Young, K. M., Fogarty, M., Kessaris, N., and Richardson, W. D. (2007). Subventricular zone stem cells are heterogeneous with respect to their embryonic origins and neurogenic fates in the adult olfactory bulb. J. Neurosci. 27, 8286-8296. doi: 10.1523/JNEUROSCI.0476-07.2007

Conflict of Interest Statement: The authors declare that the research was conducted in the absence of any commercial or financial relationships that could be construed as a potential conflict of interest.

Received: 08 January 2014; paper pending published: 28 January 2014; accepted: 07 February 2014; published online: 25 February 2014.

Citation: Giachino C and Taylor V (2014) Notching up neural stem cell homogeneity in homeostasis and disease. Front. Neurosci. 8:32. doi: 10.3389/fnins.2014.00032

This article was submitted to Neurogenesis, a section of the journal Frontiers in Neuroscience.

Copyright (๑) 2014 Giachino and Taylor. This is an open-access article distributed under the terms of the Creative Commons Attribution License (CC BY). The use, distribution or reproduction in other forums is permitted, provided the original author(s) or licensor are credited and that the original publication in this journal is cited, in accordance with accepted academic practice. No use, distribution or reproduction is permitted which does not comply with these terms. 